\title{
Tour of dental therapy in America
}

\author{
Lloyd A. Wallin* \\ School of Dentistry, University of Minnesota, USA
}

December 2, 2013

The Pew Corporate Trusts

901 East Street NW

Washington, DC 20004

RE: Tour of Dental Therapy in America

\section{To Whom It May Concern:}

I write to address areas of Minnesota's Dental Therapist Program that are continually being brushed under the carpet. Areas that I doubt will be fairly and openly discussed during your meeting at the Radisson Plaza Hotel in Minneapolis on December 6 and 7, 2013. Beginning in 2009 , the concerns of practicing dentists, such as myself, have been avoided by the public media. If you (THE PEW CORPORATE TRUST) are truly driven by the power of knowledge to solve today's most challenging problems, I invite you to read on.

\section{Preface}

It has been suggested that Minnesota has an underserved population that does not have access to dentists because "they" live in remote areas. It has been suggested that Minnesota cannot afford to treat the underserved population using licensed dentists. In 2009 the Minnesota Legislature gave the State the go ahead to train dental therapists with the intent of alleviating the alleged pain and suffering of the underserved populations throughout the State.

\section{A quick look at the background of Minnesota's Dental Therapist Initiative}

As in many parts of the Country, Minnesota Dentists have always been willing and interested in providing quality dental care to its low income population. For over ten years Minnesota Dentists annually pay to Minnesota's Healthcare Access Fund more than enough money to cover the costs of dental care for the underserved via the $2 \%$ Minnesota Health Care Provider Tax. This tax is collected quarterly by the State from every practicing dentist, and represents today $2 \%$ of their annual collections.

Unfortunately Minnesota's Governors have diverted more than seventy percent $(70 \%)$ of the provider tax collected from dentists to "other" State expenses leaving the State's low income population severely financially abandoned. Special interests then blame dentists for charging too much, not being available, and then go further to advocate the dental therapist as "the solution to the problem." In 2010, 57 million dollars was collected from dentists, but only 17 million dollars was used for low income patients.

There are more than enough licensed dentists in Minnesota who are both willing and able to treat low income patients if the State would simply pay them fairly. Recently the State Auditor for the Minnesota
Department of Human Services concluded in his report that "Minnesota dentists that take Medical Assistance (Welfare) Patients are among the lowest paid in the Country." Teachers are paid fairly, so are lawyers and physicians.

\section{A quick look at the role of "Academia" in Minnesota's Dental Therapy Program}

Everywhere we see academia performing more like a for profit business than a circle of colleges wanting to improve the intellectual capacity of their community and staff. This is especially true in Minnesota where upon graduation there are no jobs for most graduates. Our graduating dentists, in turn, are being dumped into a health care market where there are already too many dentists.

In addition, many dentists are not retiring as early as they used to because of economic issues. At the same time the American Dental Association tells us that "fewer adults are visiting the dentist," and probable for similar economic reasons [ADA News, March 18, 2013]. This combination of events is leading to overtreatment in the name of "prevention," and if left unchecked, this writer believes this, alone, will ruin the hard earned reputation of the American Dental Profession.

As a result of this oversupply of dentists in Minnesota, I am frequently seeing patients come in for "second opinions" because their regular dentists are recommending crowns they were previously never informed about, and they are fast becoming suspicious as to why? As a side note, three years back I asked a potential associate applicant to tell me what criteria "he would use to do a crown?" He actually told me that the "dental school" told him that "any tooth with a three or more surface restoration in it should be crowned." And for you non dentists out there attempting to understand this; I personally see, and place, a lot of three or more surface restorations in teeth that are just fine, and these teeth do not need crowns.

\section{A quick look at Minnesota's double standard for dental therapy care}

To facilitate the Dental Therapy Program to move forward, the Minnesota Board of Dentistry has created double standards for doing the same job. One set for dentists, and one set for therapists. Common sense tells us that a the standard of care for dentists with four years of dental school, cannot, should not, and would not be the same for therapists when providing non reversible procedures in restorative

Correspondence to: Lloyd A. Wallin, School of Dentistry, University of Minnesota, Practices General Dentistry at 50 East McAndrews Road, Burnsville, Minnesota 55337, USA, Tel: 952-892-5050; E-mail: lloyd@lwallin.com

Received: December 18, 2015; Accepted: January 10, 2016; Published: January 14,2016 
dentistry, oral surgery and pharmacy.

Advocates for dental therapy credentialing often compare Dentistry's need for the Dental Therapist ("DT") to that of Medicine's need for the Medical Nurse Practitioner ("MNP"), as if to say they both are the same. They are not the same, not even close! MNP's are needed to only assist Primary Care Physicians ("PCP"), because PCP's are in short supply due to too many Physicians specializing these days. Licensed, Registered Dental Assistants ("RDA") are already here, and available, to "assist" Dentists in the same manner as MNPs assist PCPS, and neither one performs non reversible procedures because they are not needed to do so.

The Board of Dentistry sidesteps the issue of standards of care by incorporating a "collaborative agreement" between what they call an "overseeing dentist" and the therapist. Does this mean the standard of care for the dentist is mysteriously transferred to the therapist, and who would be sued in a malpractice claim? The dental therapy program is full of trickery and deception on the part of the Board, which, in turn, seems to allow the program to keep moving forward.

\section{A quick look at a real conflict of interests in the dental therapy program}

A real conflict of interest exists between general dentists and specialists when it comes to endorsing the dental therapy program. Both generalists and specialists are in need of more patients that can afford to pay for quality dental care. Both generalists and specialists are available, and willing to work on the States' underserved low income population if only the State of Minnesota would pay them fairly.

Generalists in Minnesota oppose dental therapy because they, themselves, are not that busy. Although specialists are also not that busy, "specialists" knew the dental therapist would never be able to handle the complexities of treating low income patients, especially those that had not been to a dentist in years, and would have to refer to them. Since Minnesota pays specialists more than generalists, and specialists would get referrals from therapists, endorsing the dental therapy program was a win, win situation for Minnesota's specialists.

\section{A quick look at HMO interest in Minnesota's dental therapy program}

It is very interesting that all of the dental therapists that have graduated from dental therapy programs in Minnesota, are all working for HMOs in primarily metropolitan areas. They are definitely not working in the "remote and underserved areas of the State" as their advocates politicized. If future accreditation of the dental therapy program in Minnesota is not granted, even though it is not needed to continue the program, it is only a matter of time, all things considered, that HMO's will be terminating their license dentists in favor of hiring the therapist because they are less costly, and that is their bottom line.

So what has happened to dentistry's historic proclamation "what is best for the patient?" I think that if you are a dentist and are directly involved in patient care, you will do what is best for the patient based on your ability to perform the service. I believe everybody else will address this question based on "what is best for 'me'?" This will include lawmakers, third party payers, educators and politicians. I have a hard time believing this category would include the PEW Charitable Trusts. I sincerely hope that it never will.

\section{A quick evaluation of the dental therapy program}

The dental therapy program has absolutely no legitimate value because underserved patients, more often than not, present themselves with very complex treatment problems due to prolonged periods of neglect. General dentists, like myself, see this sort of thing every day. The dental therapy program does not, and cannot provide anything for the Nation's underserved children, that is not already provided, fully, by licensed dentists and their staff.

A local newspaper recently published an article dramatically portraying how a "dental therapist" successfully removed a lower front baby tooth from an 8 year old girl. Aside from the fact the tooth would have fallen out itself based on the little girl's age, how many moms and dads, and grandpas and grandmas, even the children themselves, have demonstrated the ability to do the same thing? Furthermore, I do not know of anyone who knows a dental therapist that would go to them for dental care.

If one truly has the best interests for the safety of, and for providing the best dental health possible to underserved patients, a licensed dentist is still the provider of choice. Through combined initiatives by both the Dental Hygiene Associations, the Dental Assistant Associations, the State Dental Associations, and the American Dental Association, expanded duties have been and will be developed, continually, based on need and input from the dental community, as it should be, and not from the uninformed ambitions of our political arenas.

\section{A quick closing}

The primary sales pitch for the dental therapy program around the Country is that this "midlevel dental provider" would, could and should go into the vast and remote areas of the United States where access to a dentist was not only nearly impossible, but "people were suffering." Well, there are no such places, even in Minnesota, and if a dentist is truly needed for treatment anywhere, access is always affordable and reasonable.

Furthermore, the majority of employed dental therapists in Minnesota today are not working in the alleged, remote areas of the State of Minnesota, but in established downtown metropolitan facilities. They are competing for patients with licensed dentists, while at the same time operating in violation of the American Dental Association's Patient Bill of Rights.

$$
\begin{aligned}
& \text { Respectfully submitted } \\
& \text { Dr. Lloyd A. Wallin, D.D.S. }
\end{aligned}
$$

Past Minnesota Dental Association Trustee

Past American Dental Association Delegate

LAW 